\title{
In-Space Propulsion Technology Products Ready for Infusion on NASA's Future Science Missions
}

\author{
David J. Anderson \\ NASA Glenn Research Center \\ 21000 Brookpark Road \\ Cleveland, OH 44135 \\ 216-433-8709 \\ David.J.Anderson@nasa.gov
}

\author{
Eric Pencil \\ NASA Glenn Research Center \\ 21000 Brookpark Road \\ Cleveland, OH 44135 \\ 216-977-7433 \\ Eric.J.Pencil@nasa.gov
}

\author{
Todd Peterson \\ NASA Glenn Research Center \\ 21000 Brookpark Road \\ Cleveland, OH 44135 \\ 216-433-5350 \\ Todd.T.Peterson@nasa.gov
}

\author{
Michelle M. Munk \\ NASA Langley Research Center \\ 1 North Dryden Street \\ Hampton, VA 23681 \\ 757-864-2314 \\ Michelle.M.Munk@nasa.gov
}

\begin{abstract}
Since 2001, the In-Space Propulsion Technology (ISPT) program has been developing and delivering in-space propulsion technologies that will enable or enhance NASA robotic science missions. These in-space propulsion technologies are applicable, and potentially enabling, for future NASA flagship and sample return missions currently being considered. They have a broad applicability to future competed mission solicitations. The high-temperature Advanced Material Bipropellant Rocket (AMBR) engine, providing higher performance for lower cost, was completed in 2009. Two other ISPT technologies are nearing completion of their technology development phase: 1) NASA's Evolutionary Xenon Thruster (NEXT) ion propulsion system, a 0.6-7 kW throttle-able gridded ion system; and 2) Aerocapture technology development with investments in a family of thermal protection system (TPS) materials and structures; guidance, navigation, and control (GN\&C) models of bluntbody rigid aeroshells; aerothermal effect models; and atmospheric models for Earth, Titan, Mars and Venus. This paper provides status of the technology development, applicability, and availability of in-space propulsion technologies that have recently completed their technology development and will be ready for infusion into NASA's Discovery, New Frontiers, SMD Flagship, or technology demonstration missions.
\end{abstract}

\section{TABLE OF CONTENTS}

1. INTRODUCTION .1

2. TECHNOLOGY DEVELOPMENT OVERVIEW .....................2

3. AEROCAPTURE ................................................................3

4. SOLAR ELECTRIC PROPULSION (SEP) ...........................5

5. PROPULSION COMPONENT TECHNOLOGIES ...................8

6. AdVANCED CHEMICAL PROPULSION ...............................8

7. SYSTEMS/MISSION ANALYSIS .......................................10

8. TECHNOLOGY INFUSION ..........................................11

9. CONCLUSION AND FUTURE PlanS...............................11

ACKNOWLEDGMENTS ......................................................11

REFERENCES .....................................................................12

BIOGRAPHIES ......................................................14

U.S. Government work not protected by U.S. copyright

\section{INTRODUCTION}

NASA's Planetary Science Division (PSD) missions seek to answer important science questions about our Solar System. To meet NASA's future science mission needs, the goal of the In-Space Propulsion Technology (ISPT) program is the development of new enabling propulsion technologies that cannot be reasonably achieved within the cost or schedule constraints of mission development timelines. Since 2001, the ISPT program has been developing in-space propulsion technologies that will enable and/or benefit near and midterm NASA robotic science missions by significantly reducing cost, mass, risk, and/or travel times. ISPT technologies will help deliver spacecraft to PSD's destinations of interest. In 2009, the ISPT program was tasked to start development of propulsion technologies that would enable future sample return missions.

The ISPT program focuses on technologies in the mid TRL range (TRL 3 to $6+$ range) that have a reasonable chance of reaching maturity in 4-6 years. The objective is to achieve technology readiness level (TRL) 6 and reduce risk sufficiently for mission infusion. ISPT strongly emphasizes developing propulsion products for NASA flight missions that will be ultimately manufactured by industry and made equally available to all potential users for missions and proposals.

The ISPT priorities and products are tied closely to the science roadmaps, Science Mission Directorate's (SMD) science plan, and the planetary science decadal surveys. ISPT emphasizes technology development with mission pull. In 2006, the Solar System Exploration (SSE) Roadmap[1] identified technology development needs for Solar System exploration, and described transportation technologies as highest priority. The highest priority propulsion technologies are electric propulsion and aerocapture. The priorities of the science community, with respect to propulsion technologies, are discussed in greater detail in Reference [2]. Initially, ISPT's responsibility was 
to develop technologies for Planetary Science Flagship missions (large, typically > \$1B), but in 2006 the focus evolved towards technology investments that would be applicable to New Frontiers (medium-class, typically \$500M-\$1B) and Discovery (small-class, typically, $<\$ 500 \mathrm{M}$ ) competed missions. Aerocapture (the use of aerodynamic drag for orbit capture) and electric propulsion continued to be a priority. And, the long-life lower-power Hall effect electric propulsion system was focused on meeting the needs of New Frontiers and Discovery missions.

The SSE Roadmap specifically states that "Aerocapture technologies could enable two proposed Flagship missions, and solar electric propulsion could be strongly enhancing for most missions. These technologies provide rapid access, or increased mass, to the outer Solar System."[1] Electric propulsion and aerocapture are suited for enabling significant science return for the outer planetary moons under investigation. The ISPT technologies are quantified to allow greater science return with reduced travel times. Excerpts from the science community are discussed in more detail in Reference [2]

Looking towards ISPT's future, the 2011 Planetary Science Decadal Survey[3] was released in March of 2011. It will provide guidance for ISPT's future technology investments. This Decadal Survey made many references to ISPT technologies such as aerocapture, NEXT, AMBR, and advancements made in the areas of astrodynamics, mission trajectory and planning tools. This Decadal Survey validated the technology investments ISPT has made over the last 10 years, and it provides ISPT with a new focus for the next decade.

The Decadal Survey Committee supported NASA developing a multi-mission technology investment program that will "preserve its focus on fundamental system capabilities rather than solely on individual technology tasks.” They highlighted the NEXT system development as an example of this "integrated approach" of "advancement of solar electric propulsion systems to enable wide variety of new missions throughout the solar system.” The Survey members made a recommendation for "making similar equivalent systems investments" in advanced solar array technology and aerocapture. In the Decadal Survey Report, the importance of developing those system technologies to TRL 6 was discussed.

One recommendation from the Decadal Survey Committee was for "a balanced mix of Discovery, New Frontiers, and Flagship missions, enabling both a steady stream of new discoveries and the capability to address larger challenges like sample return missions and outer planet exploration.” These broad mission needs would in turn require a balanced set of multi-mission technologies and integrated system capabilities. The Committee acknowledges that a "robust Discovery and New Frontiers Program would be substantially enhanced by such a commitment to multi- mission technologies.” They identified the Flagship mission technology needs for Uranus and Neptune.

This paper provides a brief overview of the ISPT program, describing the planning and development status of in-space propulsion technologies in the areas of electric propulsion, aerocapture, advanced propulsion technologies, and mission/systems analysis. These in-space propulsion technologies are applicable, and potentially enabling for future NASA flagship and sample return missions currently under consideration, as well as having broad applicability to future Discovery and New Frontiers mission solicitations. For more background on ISPT, please see References $[4,5,6]$.

\section{TeChNOLOgy DeVelopMENT OVERVIEW}

The ISPT program is currently completing the development efforts in four technology areas. They include Advanced Chemical Propulsion, Aerocapture, Electric Propulsion, and Systems/Mission Analysis. Aerocapture technology developments provide better models for: 1) guidance, navigation, and control (GN\&C) of blunt body rigid aeroshells, 2) atmosphere models for Earth, Titan, Mars and Venus, and 3) models for aerothermal effects. In addition to enhancing the technology readiness level (TRL) of rigid aeroshells, improvements were made in understanding and applying inflatable aerocapture concepts. Aerocapture technology was a contender for flight validation on NASA's New Millennium ST9 mission.

Electric propulsion (EP) technology development activities focus on completing NASA's Evolutionary Xenon Thruster (NEXT) ion propulsion system. The NEXT system was selected under a competitive solicitation for an EP system applicable to a Flagship mission. NEXT is a $0.6-7-\mathrm{kW}$ throttle-able gridded ion system suitable for future Discovery, New Frontiers, and Flagship missions. At a component level, ISPT is pursuing the development of a lightweight reliable xenon flow control system as well as standardized EP component designs.

The ISPT program continues the development of other electric propulsion products, such as the High-Voltage Hall Accelerator (HIVHAC) thruster. The HIVHAC thruster is designed as a low cost, highly reliable thruster suited for cost-capped NASA Discovery and New Frontiers class missions.[7] The HIVHAC thruster is described in more detail in ISPT's sample return propulsion paper for the 2012 IEEE Aerospace Conference.[8, 9].

The primary technology development in advanced chemical propulsion is the development of the Advanced Material Bipropellant Rocket (AMBR) engine. Its developmental activities were completed in 2009. Advanced chemical propulsion investments include the demonstration of activemixture-ratio-control and lightweight tank technology. The advanced chemical propulsion technologies have an opportunity for rapid-technology infusion with minimal risk and broad mission applicability. 
The systems analysis technology area performs numerous mission and system studies to guide technology investments and quantify the return on investment. Tool development includes the development of low-thrust trajectory tools (LTTT). This is a suite of computer programs optimized for developing mission trajectories using EP. An aerocapture "quicklook" tool was developed to quickly assess aerocapture applicability on future mission concepts. Recent focus of the systems analysis area is on developing tools to assist technology infusion. It is one of ISPT's objectives that all ISPT products be ultimately manufactured by industry and made equally available to all potential users for missions and proposals.

\section{Aerocapture}

Aerocapture is the process of entering the atmosphere of a target body to obtain a change in velocity $(\Delta \mathrm{V})$ from aerodynamic drag to slow down and capture the spacecraft in a planetary orbit. Aerocapture is the next step beyond aerobraking. Aerobraking relies on multiple passes through the upper atmosphere (once a spacecraft is captured propulsively into a high ellipse) to reduce orbital energy and circularize its orbit. Aerobraking was used at Mars on multiple orbiter missions. Aerocapture, illustrated in Figure 1 , maximizes the benefit from the atmosphere by capturing into a useful science orbit in a single pass. Aerocapture flies at a lower altitude where the atmosphere is more dense, and therefore the resultant drag and heating is higher than for aerobraking. This requires an aeroshell to both protect the spacecraft from the environment, and provide an aerodynamic surface for control during the pass. Keys to successful aerocapture are accurate arrival state knowledge, validated atmospheric models, sufficient vehicle control authority (i.e. lift-to-drag ratio), and robust guidance during the maneuver. A lightweight thermal protection system and structure will maximize the aerocapture mass benefits. Aerocapture significantly reduces the chemical propulsion requirements of an orbit capture.

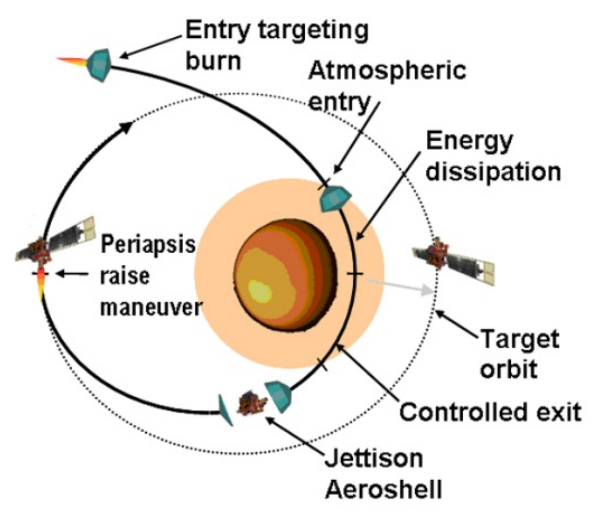

Figure 1 - Illustration of the aerocapture maneuver

Executing the aerocapture maneuver itself enables the great mass savings over other orbital insertion methods. If the hardware subsystems are not mass efficient, or if performance is so poor that additional propellant is needed to adjust the final orbit, the benefits can be significantly reduced. ISPT efforts in aerocapture subcomponent technologies focus on improving the efficiency and number of suitable alternatives for aeroshell structures and ablative thermal protection systems (TPS). These include development of families of low and medium density (14-36 lbs/ft3) TPS and the related sensors, development of a carbon-carbon rib-stiffened rigid aeroshell, and hightemperature honeycomb structures and adhesives. Inflatable decelerators were investigated through concept definition and initial design and testing of several inflatable decelerator candidates. Finally, progress was made through improvement of models for atmospheres, aerothermal effects, and algorithms and testing of a flight-like guidance, navigation and control (GN\&C) system.

Aerocapture has shown repeatedly in detailed analyses to be an enabling or strongly enhancing technology for several targets with atmospheres. The aerocapture project team continues to mature aerocapture components in preparation for a flight demonstration. Rapid aerocapture analysis tools are being developed and made available to a wide user community. The TPS materials developed through ISPT enhance a wide range of missions by reducing the mass of entry vehicles. The remaining gaps for technology infusion are efficient TPS for Venus, high-speed Earth return, and Neptune. All of the other component technologies for an aerocapture vehicle are currently at or funded to reach TRL 6 in the next year. This assessment of technology readiness is detailed in Reference [10], and summarized in Figure 2. The structures and TPS subsystems as well as the aerodynamic and aerothermodynamic tools and methods can be applied to small-scale entry missions even if the aerocapture maneuver is not utilized.

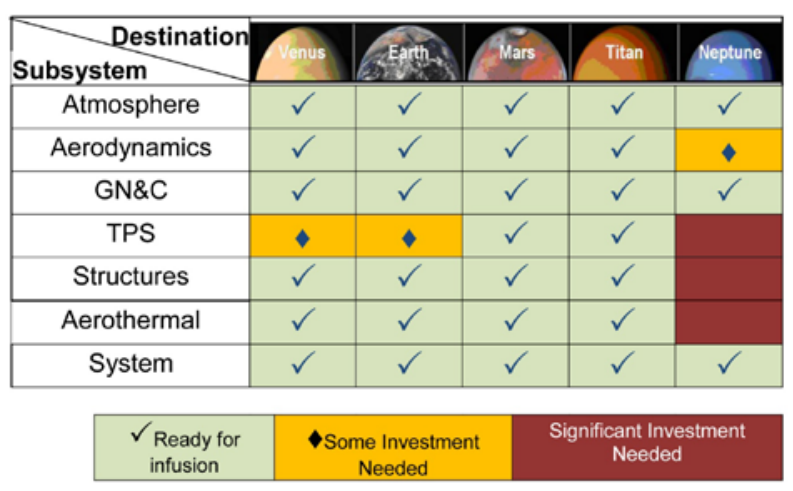

Figure 2 - Aerocapture readiness for various targets

Recent testing and development focused on maturing efficient rigid aeroshell systems. The low- and mid-density ablator systems (called "SRAM" and "PhenCarb" from Applied Research Associates, ARA) were matured by increasing the scale and complexity from the TPS subsystem to that of an aeroshell system with an underlying structure. The ablators were tested at both NASA Ames 
Research Center's (ARC) arcjet and Sandia National Labs' solar-tower facilities in the form of 5-in coupons, and 1-ft and 2-ft square flat panels. Both TPS families were applied to one-meter, 70 degree, high-temperature blunt body aeroshell structures from ATK, as shown in Figure 3, to demonstrate manufacturability of a representative shape.

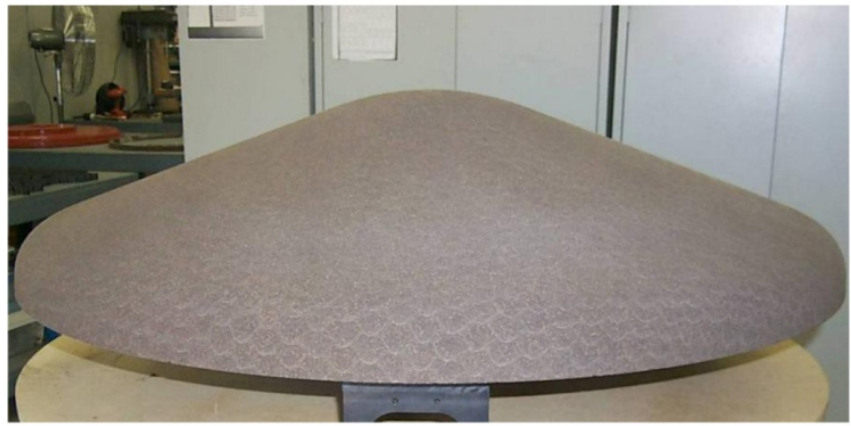

Figure 3 - 1.0-meter aeroshell with SRAM TPS

As flight aeroshells become larger (over 3 meters in diameter), it is more difficult to hand-pack them, as was done with the Apollo capsules and every successful Mars heatshield to date. ARA developed a modular TPS approach, in which large modules of TPS are pre-packed into honeycomb, cured, and precisely milled to fit the aeroshell structure. Because SRAM and PhenCarb are somewhat elastic, a small number of modules (less than ten) are needed to cover the aeroshell. Gaps between modules are packed with the same ablator and cured. The result is a seamless aeroshell. To mature this approach, ISPT is manufacturing a 2.65-meter (Discovery-class size) lowdensity heatshield. The TPS is applied to the ATK 400 degree-C bondline structure. This demonstration unit is in its final manufacturing stages (Figure 4). It is scheduled for completion in mid-2012. Lawrence Livermore National Laboratory (LLNL) scientists will perform a non-destructive scan of the completed aeroshell to mature such diagnostic methods. Manufacturing at this scale will mature the hightemperature aeroshell system to TRL 5.

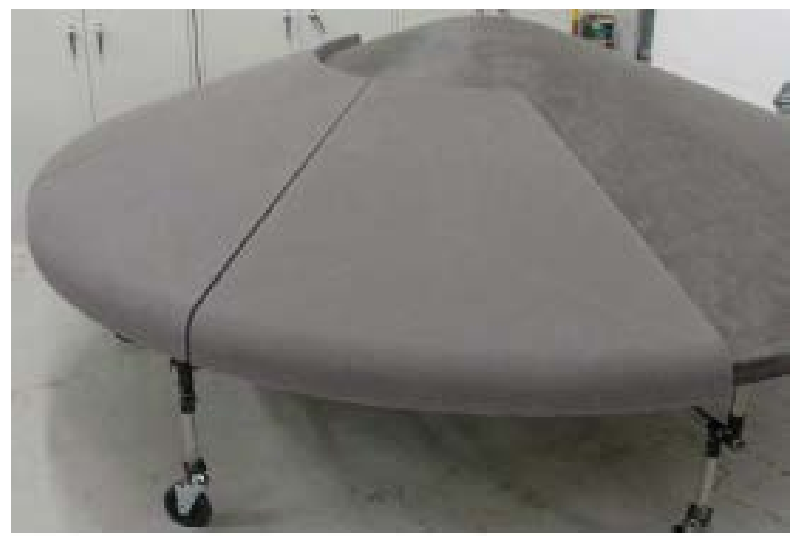

Figure 4 - Fit check of TPS modules on 2.65-m aeroshell.
The SRAM TPS on the 2.65-meter article will be outfitted with instrumented thermal plugs. These are similar to the plugs included on the Mars Science Laboratory as part of the MEDLI (MSL Entry, Descent and Landing Instrumentation) suite. The included sensors measure TPS recession with sub-millimeter accuracy. The sensors were developed at NASA ARC under ISPT funding. The instrumentation of entry systems to gather flight data is of primary importance to understand the system performance, environments, and vehicle requirements for future missions.

The precursor, or test unit, for the 2.65-meter modular SRAM aeroshell was a modular PhenCarb one-meter aeroshell. This unit underwent thermostructural testing at the Sandia National Labs solar tower facilities in March 2011 (Figure 5). The unit was scanned by LLNL before and after the thermostructural testing.

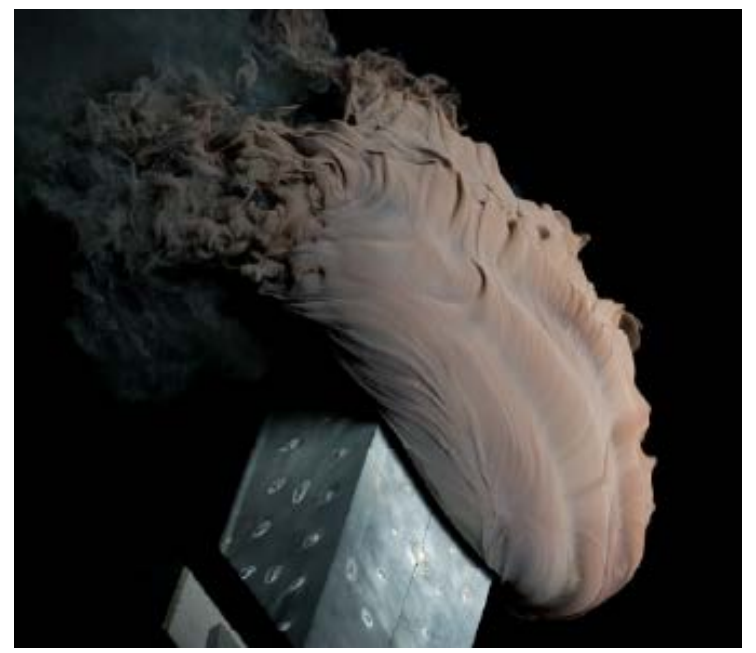

Figure 5 - One-meter PhenCarb Aeroshell Testing at
Sandia

Another effort to raise the TRL for TPS materials includes Space Environmental Effects (SEE) testing. Conducted at the Marshall Space Flight Center and the White Sands Test Facility (WSTF), this testing includes radiation exposure, cold soak, and micrometeoroid impact on the ISPT-matured TPS and hot structure materials, to levels representative of a deep space mission. Figure 6 shows the shroud manufactured to cold soak the samples prior to a micrometeoroid impact of $7-\mathrm{km} / \mathrm{s}$. Following exposure to these environments, samples will be arcjet tested to aerocapture heat rates and loads, in the Interaction Heating Facility at NASA-Ames. The results will be compared to arcjet tests of unexposed samples. The testing is expected to be complete by the summer of 2012. Additional information on aerocapture technology developments can be found in the Discovery Program library,[11] and in References [1217]. 


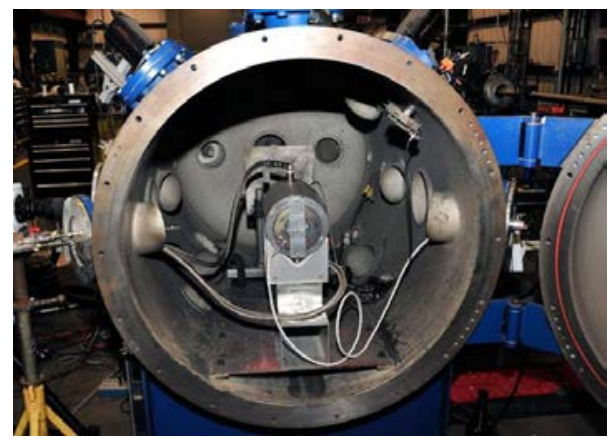

Figure 6 - Cold shroud for micrometeroroid testing (facility located at WSTF).

\section{Mission Benefits}

The use of aerocapture was studied extensively, most notably for use at Titan, Neptune, Venus and Mars. Figure 7 shows the anticipated increases in delivered mass. The largest mass benefit from aerocapture was observed for Neptune, low Jupiter orbits, followed by Titan, Uranus, Venus, and then only marginal gains for Mars (the mass benefit is directly correlated to the amount of velocity change required for each mission). Alternatively, cost benefits are realized for multiple missions using aerocapture. When the overall system mass is reduced, the mission can utilize a smaller launch vehicle, saving tens of millions of dollars. Detailed mission assessment results are in References [18-20].

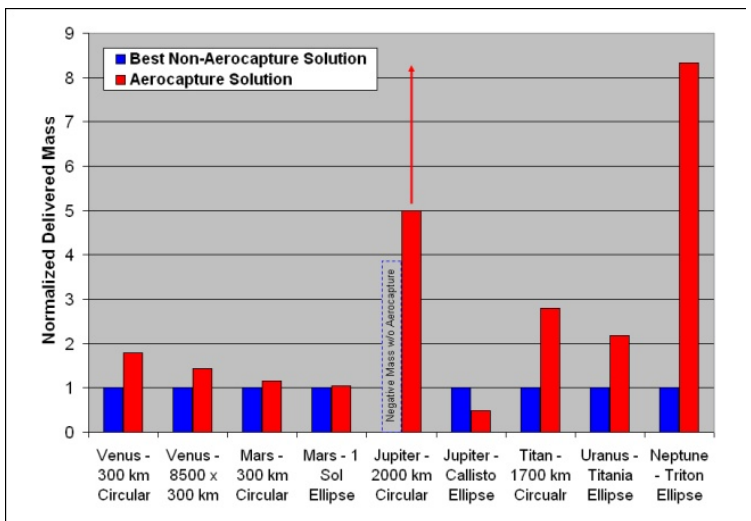

Figure 7 - Aerocapture benefits for various targets.

The mission mass benefits to Mars are expected to be about 5-15 percent, depending on the scale of the spacecraft. These benefits can be enabling. A multi-center team from Ames Research Center (ARC), Jet Propulsion Laboratory (JPL), Johnson Space Center (JSC), Langley Research Center (LaRC), and MSFC conducted detailed mission and cost analyses for various Mars opportunities. An oppositionclass sample return mission that takes less than two years is enabled by aerocapture. Aerocapture enhances conjunctionclass sample-return missions and large Mars orbiters. No new technology gaps are identified that delay aerocapture implementation on such a mission.
Venus was studied extensively to identify any needs for TPS, guidance, atmospheric or heating models. Detailed analyses evaluated the potential for aerocapture for a Venus Discovery class mission. In this case, aerocapture delivered more than 80 percent additional mass over chemical propulsion combined with aerobraking, and it delivered more than 600 percent over a chemical propulsion only case. The use of aerocapture reduced the Deep Space Network (DSN) time by 121 days. No critical technology gaps were identified for aerocapture at Venus, but investments in TPS are recommended for achieving maximum mass benefits.

Titan continues to be of considerable scientific interest following the success of Cassini/Huygens. Because of its atmospheric structure, it is an ideal candidate for aerocapture. The Outer Planets Flagship (OPF) study considers aerocapture within the baseline mission concept because aerocapture has the capability to deliver more than double the scientific payload of the chemical-propulsion only alternative. Additionally, aerocapture may play a key role in accomplishing a reduced Titan mission for a lessthan-Flagship budget or providing an alternate Flagship operational scenario.

Aerocapture as a complete system capability cannot reach TRL 6 without space flight validation, because it is impractical to match the flight environment in ground facilities. This validation can be accomplished by utilizing aerocapture on a science mission, or by a dedicated space flight validation experiment. SMD has incentivized the use of aerocapture in its recent Discovery Announcement of Opportunity (AO). Because a Discovery mission utilizing aerocapture was not selected in 2011, aerocapture will likely seek other opportunities to be validated in space. A space flight validation is expensive, but the costs will be recouped very quickly if just one mission's launch vehicle cost is reduced as a result of the lower mass requirement enabled by aerocapture. The validation immediately reduces the risk to the first user and matures the maneuver for application to multiple, potentially lower-cost, missions to Titan, Mars, Venus, and Earth.

Using aerocapture produces significant cost benefits for multiple missions. When the overall system mass is reduced, the mission can utilize a smaller launch vehicle saving tens of millions of dollars. Detailed mission assessment results can be found in the aerocapture-related references in Reference [5]. Once aerocapture is proven a reliable capability, it is anticipated that entirely new sets of missions will become possible.

\section{Solar Electric Propulsion (SEP)}

Electric propulsion is both an enabling and enhancing technology for reaching a wide range of targets. Several key missions of interest: sample return, small body rendezvous, multi-rendezvous, TSSM, Uranus Orbiter w/Probe, etc., require significant post-launch $\Delta \mathrm{V}$ and therefore can benefit greatly from the use of electric propulsion.[21-22] High 
performance in-space propulsion can also enable launch vehicle step down; significantly reducing mission cost.[23] The performances of the electric propulsion systems allow direct trajectories to multiple targets that are otherwise infeasible using chemical propulsion. The technology allows for multiple rendezvous missions in place of fly-bys, and as planned in the Dawn mission, can enable multiple destinations.

This technology offers major performance gains, moderate development risk, and significant impact on the capabilities of new missions. Current plans include completion of the NASA's Evolutionary Xenon Thruster (NEXT) Ion Propulsion System targeted at Flagship, New Frontiers and demanding Discovery missions.

The GRC-led NEXT project was competitively selected to develop a nominal 40-cm gridded-ion electric propulsion system.[5] The objectives of this development were 1) to improve upon the state-of-art (SOA) NASA Solar Electric Propulsion Technology Application Readiness (NSTAR) system flown on Deep Space-1 and Dawn, 2) to enable flagship class missions by achieving the performance characteristics listed in Table 1.

The ion propulsion system components developed under the NEXT task include the ion thruster, the power-processing unit (PPU), the feed system, and a gimbal mechanism. The NEXT project is developing prototype-model (PM) fidelity thrusters through the Aerojet Corporation. In addition to the technical goals, the project has the goal of transitioning thruster-manufacturing capability with predictable yields to an industrial source. To demonstrate the performance and life of the NEXT thruster, a test program is underway. The
NEXT PM thruster completed a short-duration test in which overall ion-engine performance was steady with no indication of performance degradation. A NEXT PM thruster has passed qualification level environmental testing (Figure 8). As of November 302011 the Long Duration Test (LDT) of the NEXT engineering model (EM) thruster achieved over 664-kg xenon throughput, $25.2 \times 10^{6} \mathrm{~N}$-s of total impulse, and over 38,000 hours at multiple throttle conditions. (Figure 9) The NEXT LDT wear test is demonstrating the largest total impulse ever achieved by a gridded-ion thruster. ISPT funding for the thruster life test continues through FY12 and FY13. The goal is to demonstrate thruster operation through the anticipated first failure mode (structural failure of the ion optics) which is anticipated at $>750 \mathrm{~kg}$ of xenon throughput at full power conditions. A post-test inspection of the hardware will be conducted in FY13.[24]

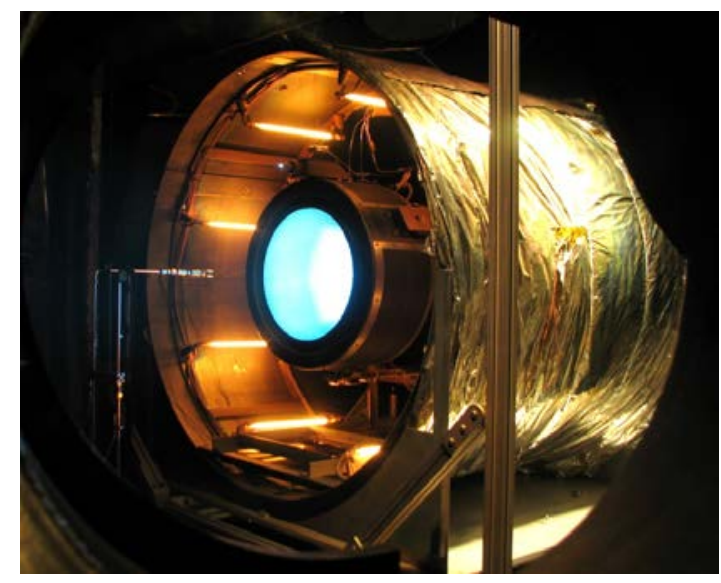

Figure 8 - NEXT thermal vacuum testing at JPL

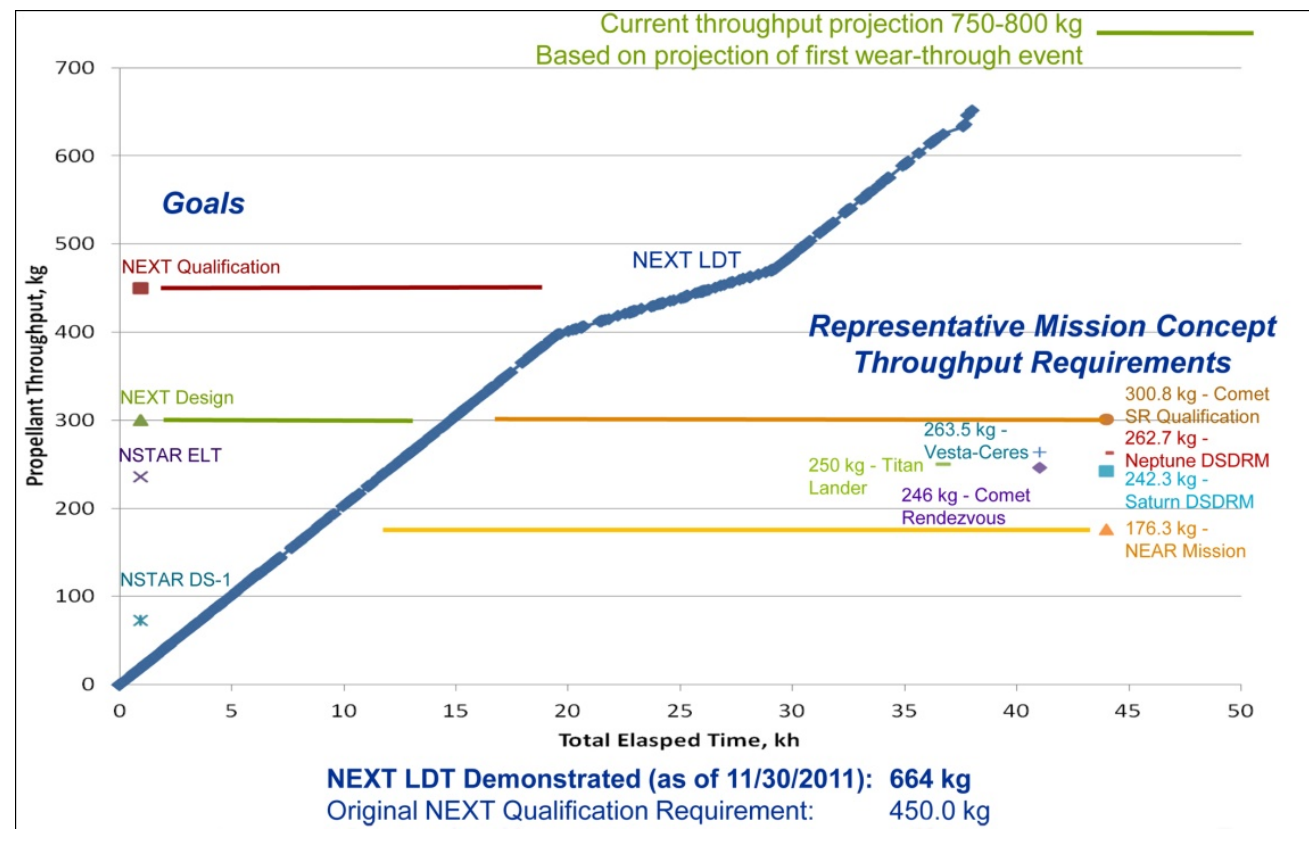

Figure 9 - Next Thruster Total Throughput versus representative mission requirements 
One of the challenges of developing the NEXT ion propulsion system was the development of the Engineering Model PPU. The demanding test program has flushed out a number of part problems that required extensive investigations to resolve and implement corrective actions.[25] It should be noted that such part problems are not unique in a technology development phase, and can still be experienced in the transition-to-flight hardware development phase. Technology development projects like NEXT are trying to identify and mitigate these kinds of issues, before the PPU moves into a flight development phase.

The first PPU part problem was a diode failure in the beam module output supply. In this instance the investigation team discovered that a diode procured from a second vendor did not have the same electrical characteristics as the diodes from the primary source. The electrical characteristics published on the specification sheet were acceptable; however, the electrical specifications, like reverse-recovery time, which were not listed in the part specification sheet, were not acceptable for the particular design application. The corrective action was to replace the second-source diodes.

A second PPU part problem was the catastrophic failure of the multi-layer ceramic (MLC) capacitor in multiple beam power supplies. The investigation process required a large team that investigated all branches of the fault tree. The corrective actions identified that a custom-built MLC had piezoelectric properties that made it susceptible to an oscillating current in the beam supply circuit. The corrective actions in this case were to replace the custom-build MLC capacitor as well as to eliminate the oscillating current. Recently, another part problem was uncovered, which manifested itself as a shorted diode. The preliminary diagnosis was that a void in the printed circuit board may have contributed to an overvoltage condition on the diode which caused it to short. However, the preliminary conclusions still need to be confirmed with x-ray inspection of the printed circuit board. The corrective actions for the diode and MLC capacitor issues were implemented in the EM PPU, and this resolved the problems. The investigation continues for the latest diode/printed circuit board problem.

Additional information on the NEXT system can be found in the NEXT Ion Propulsion System Information Summary in the New Frontiers and Discovery Program libraries.[11,24,26]

\section{NEXT Mission Benefits}

In the original solicitation NEXT was selected as an electric propulsion system for flagship missions. To that end, NEXT is the most capable electric propulsion system ever developed. A single NEXT thruster:

- $\quad$ uses seven kilowatts of power (max),

- has an estimated propellant throughput capability of over $750 \mathrm{~kg}$,
- has a lifetime of over 35,000 hours of full power operation,

- $\quad$ has a total impulse capability of approximately 30 million N-s, or about three times that of the SOA DAWN thrusters.

This performance leads to benefits for a wide range of potential mission applications.

The NEXT thruster has clear mission advantages for very challenging missions. For example, the Dawn Discovery Mission only operates one NSTAR thruster at a time, but requires a second thruster for throughput capability. For the same mission, the NEXT thruster could deliver mass, equivalent to doubling the science package, with only a single thruster. Reducing the number of thrusters reduces propulsion system complexity and spacecraft integration challenges. The NEXT thruster can enable lower cost implementation by eliminating system complexity. Comparisons between the State-of-the-Art (SOA) NSTAR thruster and the NEXT thruster are shown below in Table 1.

The missions that are improved through the use of the NEXT thruster are those requiring significant $\Delta \mathrm{V}$, such as sample returns, highly inclined, or deep-space rendezvous missions. The comet sample-return mission was studied for several destinations because of its high priority within the New Frontiers mission category. Electric propulsion enables a much wider range of feasible targets. Specifically for Temple 1 in Reference [5], the NSTAR thruster is able to complete the mission, but it requires large solar arrays and four or five thrusters to deliver the required payload. NEXT would be able to deliver ten percent more total mass and require half the number of thrusters.

Table 1. Performance comparison of NSTAR and NEXT ion thrusters

\begin{tabular}{|lcc|}
\hline \multicolumn{1}{|c}{ Characteristic } & $\begin{array}{c}\text { NSTAR } \\
\text { (SOA) }\end{array}$ & NEXT \\
\hline Max. Thruster Power (kW) & 2.3 & 6.9 \\
\hline Max. Thrust (mN) & 91 & 236 \\
\hline Throttle Range (Max./Min. Thrust) & 4.9 & 13.8 \\
\hline Max. Specific Impulse (sec) & 3120 & 4190 \\
\hline Total Impulse (x10 ${ }^{6}$ N-sec) & $>5$ & $>18$ \\
\hline Propellant Throughput (kg) & 200 & 750 \\
\hline
\end{tabular}

NEXT can not only deliver larger payloads, but can reduce trip times and increase launch window flexibility. Chemical options exist for several missions of interest. However, the large payload requirements of flagship missions often require multiple gravity assists that both increase trip time and decrease the launch opportunities. 
The Titan Saturn System Mission is an example mission where SEP combined with multiple gravity assists can eliminate the need for Aerocapture. Significant increase in payloads are possible using SEP for the Saturn, Uranus, and Neptune systems.[27,28] SEP for Titan and Uranus can perform orbit insertion without aerocapture and dramatically improve delivered mass or reduce trip times for Neptune with Aerocapture. Using NEXT on a SEP stage for Titan can deliver sufficient mass to perform an orbit insertion maneuver prior to separating the Montgolfier balloon and lander from the orbit, reducing mission risk.

The ISPT portfolio consists of the NEXT system, HIVHAC thruster[5], and other component improvements. These technologies offer electric propulsion solutions for scientific missions previously unattainable. Scientists can open their options to highly inclined regions of space, sample return or multi-orbiter missions, or even deep-space rendezvous missions with more science and reduced trip times.

\section{Propulsion Component Technologies}

NASA's In-Space Propulsion Technology program has invested in an Advanced Xenon Feed System (AXFS) for electric propulsion systems. The feed system is designed for an increased reliability combined with a decrease in system mass, volume, and cost as compared to SOA flight systems and comparable TRL 6 technology. The final development module, the pressure control module (PCM), was completed in 2007. The Naval Research Laboratory (NRL) completed functional and environmental testing of the VACCO PCM in September of 2008. Following the environmental testing, the PCM was integrated with the Flow Control Modules (FCM) and an integrated AXFS (with controller) was delivered to the project. NASA GRC completed hot-fire testing of the AXFS with the HIVHAC Hall thruster. This test successfully demonstrated hot-fire operation using closed-loop control with downstream pressure feedback and with the Hall thruster discharge current. Follow-on testing will determine the viability of the AXFS to perform singlestage single-module control from high-pressure xenon directly to a thruster.

To continue to simplify and reduce the cost of future electric propulsion systems, the ISPT program is leveraging its investments in its reliable, lightweight, and low-cost xenon flow control system for a simplified control module. A follow-on contract was awarded to VACCO as a joint ISPT and Air Force effort to qualify a Hall system module. This module would significantly reduce the cost, mass, and volume of a Hall thruster xenon control system while maintaining high reliability and decreasing tank residuals. This is the first time the ISPT program advanced a component technology to TRL 8 to further reduce the risk and cost of the first user. The new Hall module is shown in Figure 10. The Hall module is scheduled to complete its qualification program in March 2011. The module is planned for inclusion in a long-duration test as an integrated-string test of the HIVHAC system. A second unit (an acceptance tested flight unit) has been ordered and should be delivered in December 2012.

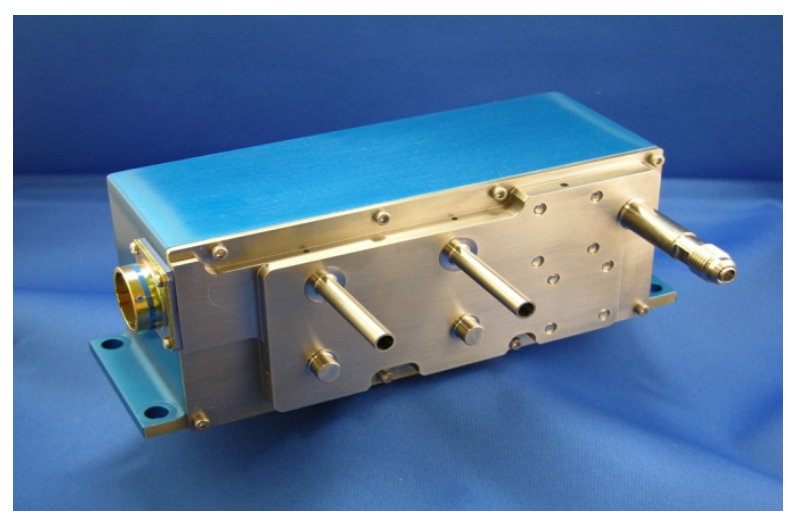

Figure 10. VACCO xenon flow control module.

The AXFS technology is ready for transition into a qualification program. It achieves its objective[29] by demonstrating accurate xenon control with significant system reduction in mass and volume through the use of integrated modules for low-cost control options and/or reliability beyond practical SOA technology implementation. The resultant feed system represents a dramatic improvement over the NSTAR flight-feed system. It demonstrates an additional 70 percent reduction in mass, 50 percent reduction in footprint, and 50 percent reduction in cost over the baseline NEXT feed system at TRL 6. The project successfully completed the integrated system testing and advanced the modules to TRL 6.[30]

\section{Advanced Chemical Propulsion}

ISPT's approach to the development of chemical propulsion technologies is primarily the evolution of component technologies that still offers significant performance improvements. The investments focus on items that would provide performance benefit with minimal risk with respect to the technology being incorporated into future fight systems. Reference [31] has a thorough description of the complete Advanced Chemical Propulsion effort that was concluded in 2009.

The single largest investment within the advanced chemical propulsion technology area was the Advanced Materials Bipropellant Rocket (AMBR) engine (Figure 11). It was awarded, through a competitive process, to Aerojet Corporation in FY2006. The AMBR engine is a high temperature thruster that aimed to address cost and manufacturability challenges of using iridium coated rhenium chambers. The project includes the manufacture and hot-fire tests of a prototype engine demonstrating increase performance and validating new manufacturing techniques.[32] Performance testing was conducted on the AMBR engine in October 2008 and February 2009 with long duration testing in June 2009. The thruster demonstrated an $\mathrm{I}_{\mathrm{sp}}$ of 333 seconds at $141 \mathrm{lbf}$ thrust,[32] which is the highest ever achieved for hydrazine/NTO 
(nitrogen tetroxide) propellant combination (Figure 12). The project completed vibration shock, and long-duration testing to raise the TRL to 6 . Additional information is found in the AMBR information summary in the New Frontiers and Discovery program libraries. [11,26,33]

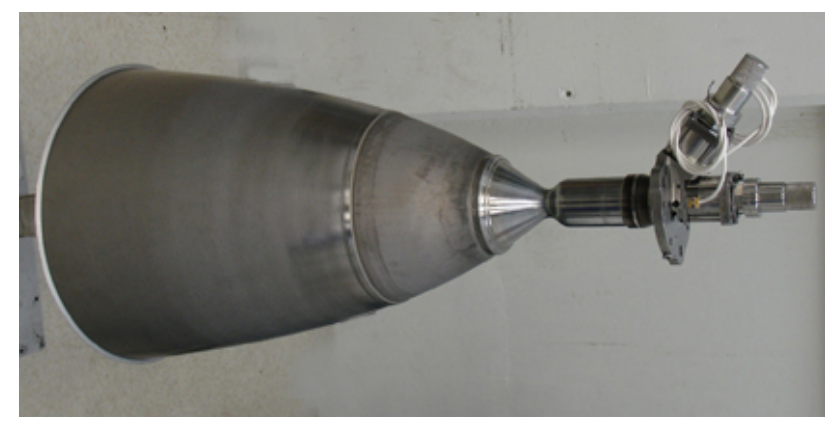

Figure 11 - AMBR engine test article

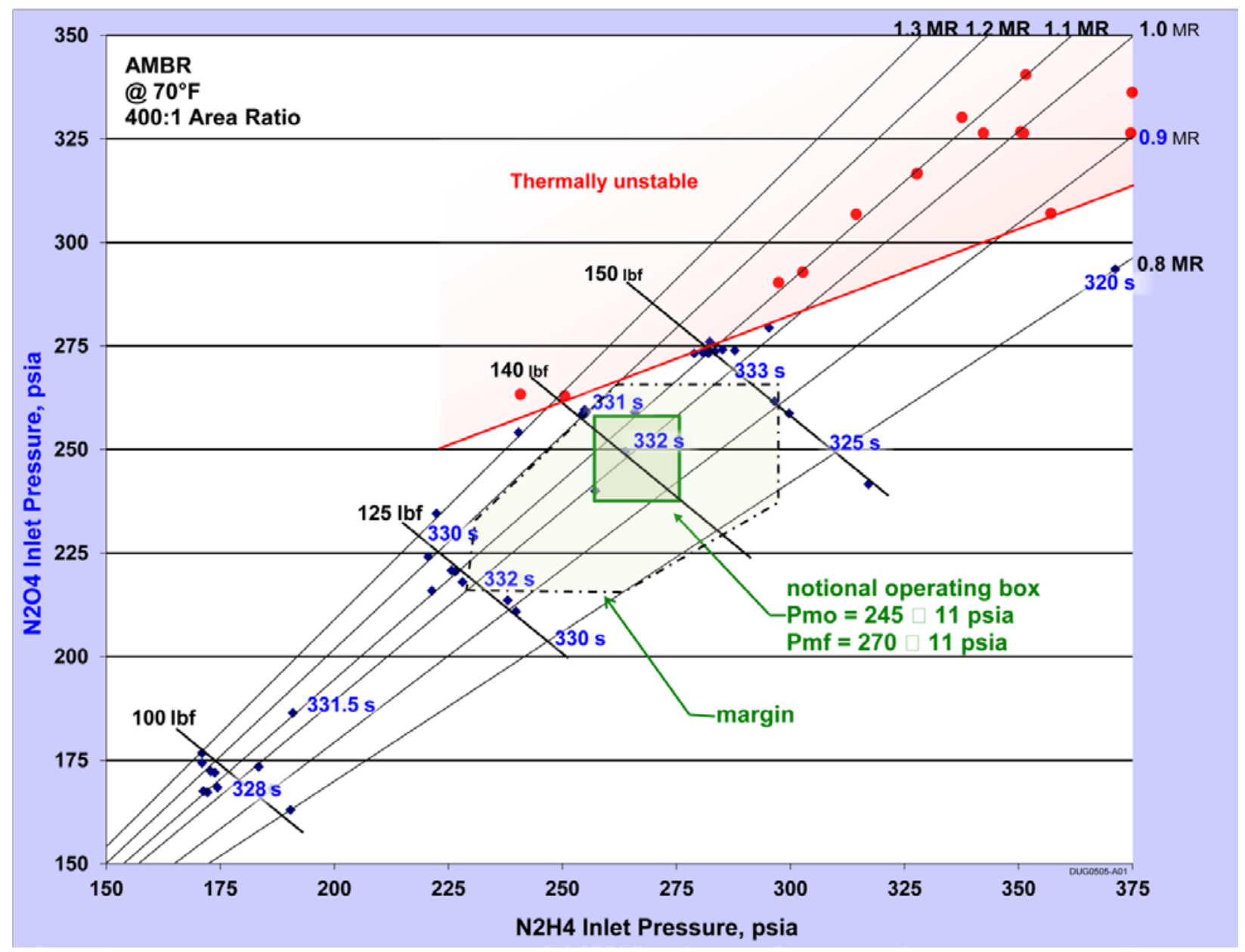

Figure 12 - Notional operating box for AMBR engine..

\section{AMBR Mission Benefits}

The mission benefits in the area of advanced chemical propulsion are synergistic, and the cumulative effects have tremendous potential for deep space missions. The infusion of the individual components separately provides reduced risk, or combined provides considerable payload mass benefits.
The AMBR engine development significantly benefits missions with large propulsion maneuvers through the reduction of wet mass.[34] In addition, the expectation for the AMBR engine is to have a 30 percent cost reduction in the combustion chamber manufacturing with an increase in performance. The mission mass benefits are dependent on the mission-required $\Delta \mathrm{V}$, but are easily about the size of scientific instrument packages flown on previous missions. 
Figure 13 shows potential payload increases due to the increased specific impulse and thrust for multiple missions. For a mission like Cassini, a higher thrust engine can reduce complexity by reducing the number of thrusters. The system would deliver additional mass, over $50 \mathrm{~kg}$; which equates to a potential increase in scientific payload by 100 percent.

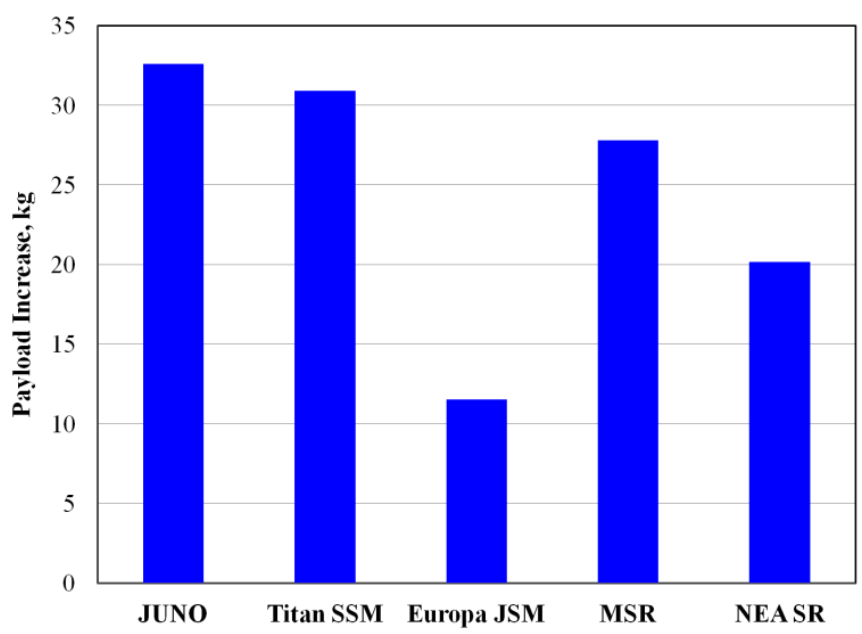

Figure 13 - Mass Benefits from the AMBR engine.

\section{SySTEMS/MisSiOn ANALYSIS}

Systems analysis is used during all phases of any propulsion hardware development. The systems analysis area serves two primary functions:

1) to help define the requirements for new technology development and the figures of merit to prioritize the return on investment,

2) to develop new tools to easily and accurately determine the mission benefits of new propulsion technologies allowing a more rapid infusion of the propulsion products.

Systems analysis is critical prior to investing in technology development. In today's environment, advanced technology must maintain its relevance through mission pull. Systems analysis is used to identify the future mission needs for decadal missions and Discovery design reference mission (DRMs). The mission studies identify technology gaps, and are used to quantify mission benefits at the system level. This allows studies to guide the investments and define metrics for the technology advancements. Recent systems analysis efforts include quantitative assessment of higher specific impulse Hall thrusters,[35] higher thrust-to-power gridded-ion engines, and evaluation of monopropellant system anomalies to assess failure modes and potential mitigation options. In addition to informing project decisions, the mission design studies provide an opportunity to work with the science and user community.

The second focus of the systems analysis project area is the development and maintenance of tools for the mission and systems analyses. Improved and updated tools are critical to allow the potential mission users to quantify the benefits and understand implementation of new technologies. A common set of tools increases confidence in the benefit of ISPT products both for mission planners as well as for potential proposal reviewers. For example, low-thrust trajectory analyses are critical to the infusion of new electric propulsion technology. The ability to calculate the performance benefit of complex electric propulsion missions is intrinsic to the determination of propulsion system requirements. Improved mission design tools demonstrate the ability to enable greater science with reduced risk and/or reduced transit times. Every effort is made to have the ISPT program tools validated, verified, and made publicly available. Additional information on the ISPT tools is available at the ISPT website, http://spaceflightsystems.grc.nasa.gov/Advanced/SciencePr oject/ISPT/LTTT/, including background information and instructions to request the software.

The ISPT office invested in multiple low-thrust trajectory tools that independently verify low thrust trajectories at various degrees of fidelity. The ISPT low-thrust trajectory tools (LTTT) suite includes Mystic,[36] the Mission Analysis Low Thrust Optimization (MALTO)[37] program, Copernicus,[38] and Simulated N-body Analysis Program (SNAP). SNAP is a high fidelity propagator. MALTO is a medium fidelity tool for trajectory analysis and mission design. Copernicus is suitable for both low and high fidelity analyses as a generalized spacecraft trajectory design and optimization program. Mystic is a high fidelity tool capable of N-body analysis and is the primary tool used for trajectory design, analysis, and operations of the Dawn mission. While some of the tools are export controlled, the ISPT web site does offer publicly available tools and includes instructions to request tools with distribution limitations. The ISPT systems analysis project team is conducting a series of courses for training on the ISPT supported trajectory tools. On-going tool advancements include providing MALTO and Mystic on all platforms, bug fixes, and increased capabilities.

ISPT aerocapture project released its Aerocapture Quicklook Tool, formally the multidisciplinary tool for Systems Analysis of Planetary EDL (SAPE).[39] SAPE is a Python based multidisciplinary analysis tool for entry, decent, and landing (EDL) at Venus, Earth, Mars, Jupiter, Saturn, Uranus, Neptune, and Titan. The purpose of the SAPE tool is to provide a method of rapid assessment of aerocapture or EDL system performance, characteristics, and requirements. SAPE includes integrated analysis modules for geometry, trajectory, aerodynamics, aerothermal, thermal protection system, and structural sizing. For aerocapture and EDL system designs, systems analysis teams include systems engineers and disciplinary specific experts in flight mechanics, aerodynamics, aerothermodynamics, structural analysis, and thermal protection systems (TPS). The systems analysis process may take from several weeks to years to complete. While the role of discipline experts cannot be replaced by any tool, the 
integrated capabilities of SAPE can automate and streamline several parts of the analysis process significantly reducing the time and cost for preliminary assessment. SAPE continues to receive investment for assessment of Earth Entry Vehicles.[8]

\section{TECHNOLOGY INFUSION}

The ISPT program has developed several technologies that are reaching TRL 6, and are potentially applicable for infusion into future, Flagship, New Frontiers, and Discovery mission opportunities. Three technologies in particular are: 1) the NASA's Evolutionary Xenon Thruster (NEXT) ion propulsion system, 2) the Advanced Material Bi-propellant Rocket (AMBR) engine, and 3) Aerocapture. ISPT and NASA are exploring several different paths to get its technology investments infused into future NASA, DOD, or commercial missions.

NASA recognizes that it is desirable to fly new technologies that enable new scientific investigations or to enhance an investigation's science return. The Solar System Exploration (SSE) Roadmap states that NASA will strive to maximize the payoff from its technology investments, either by enabling individual missions or by enhancing classes of missions with creative solutions. Discovery, New Frontiers, and Flagship missions potentially provide opportunities to infuse advanced technologies developed by NASA. They advance NASA's technology base and enable a broader set of future NASA, DOD, and commercial missions.

To benefit from its technology investments, NASA provided incentives for infusion of new technological capabilities that it developed in the most recent New Frontiers and Discovery competed mission solicitations. The incentives for NEXT, AMBR, and aerocapture were in the form of increases to the cost cap for the mission. The Decadal Survey states "these technologies continue to be of high value to a wide variety of solar system missions.” And that "NASA should continue to provide incentives for these technologies until they are demonstrated in flight." The 2011 Planetary Decadal Survey strongly supported continuing to incentivize these technologies until they are flown.[3] As funding and priorities allow, ISPT will strive to maintain the capabilities associated with NEXT, AMBR, and aerocapture, and ISPT will continue to look for future opportunities to infuse these technologies.

Beyond the New Frontiers and Discovery opportunities, ISPT continues to seek opportunities to infuse NEXT, AMBR, aerocapture, and its other technologies into a wide range of possible future mission opportunities. The ISPT program office and NEXT team personnel are actively supporting various flagship science definition team (SDT) studies. ISPT personnel supported several white papers that were developed in response to the current planetary science decadal survey development activities in 2009/2010. See the ISPT Overview papers from the 2010 IEEE Aerospace Conference for more details regarding these studies.[10,31] ISPT will continue to help in identifying the technology development that is required to accomplish the future missions being contemplated.

\section{Conclusion}

ISPT will complete current developments to TRL 6 in the next year, and in the future will continue to support mission infusion. Among these is the NEXT electric propulsion system The NEXT team wraps-up PPU development and testing in 2012, but continues long-duration life testing into 2013. The NEXT system is available for all future mission opportunities. The AMBR engine reached TRL 6 in 2009, and completed the final reporting and documentation in early 2010. Finally, an aerocapture system comprised of a blunt body TPS system, the GN\&C, sensors, and the supporting models achieved its technology readiness in mid 2010. Beyond completing the currently funded NEXT and aerocapture activities, future work for NEXT, AMBR, and aerocapture will be in response to being included on a selected Discovery or New Frontiers proposal or other NASA technology infusion opportunity. Regardless, if the mission requires electric propulsion, aerocapture, or a conventional chemical system, ISPT technology has the potential to provide significant mission benefits including reduced cost, risk, and trip times, while increasing the overall science capability and mission performance. Aerocapture and electric propulsion are frequently identified as enabling or enhancing technologies.

ISPT will continue to work with the Planetary Science Division (PSD) to identify the propulsion technologies that will be pursued in the future. The planetary decadal survey identified the need for future work in electric and chemical propulsion, and aerocapture. ISPT will continue to look for ways to reduce system level costs and enhance the infusion process.

\section{ACKNOWLEDGMENTS}

The results and findings presented here are based on work funded by NASA's Science Mission Directorate (SMD). The ISPT program office is located at the Glenn Research Center (GRC), and manages the ISPT program for PSD. ISPT implements the program through task agreements with NASA centers, contracts with industry, and via grants with academic institutions. Implementing NASA centers include Ames Research Center (ARC), GRC, Goddard Space Flight Center (GSFC), Jet Propulsion Laboratory (JPL), Langley Research Center (LaRC), and the Marshall Space Flight Center (MSFC). There are also numerous industry partners in the development of the ISPT products. The authors acknowledge the technical achievements by the respective NASA and contractor teams and the contributions of the respective technology area project managers. In addition, many thanks to Linda Nero for her administrative, editorial, and clerical support of this paper. 


\section{REFERENCES}

[1] "2006 Solar System Exploration Roadmap for NASA's Science Mission Directorate,” September 2006.

[2] Anderson, D. J. et. al., "The NASA In-Space Propulsion Technology Project, Products, and Mission Applicability,” 2009 IEEE Aerospace conference, March 2009, Paper \#1176.

[3] "Vision and Voyages for Planetary Science in the Decade 2013-2022," The National Academies Press, URL: http://www.nap/edu, 2011

[4] Anderson, D. J. Pencil, E. Peterson, T., Dankanich, J., Munk, M., "In-Space Propulsion Technology Products for NASA's Future Science and Exploration Missions,” 2011 IEEE Aerospace conference, March 2011, Paper \#1114.

[5] Anderson, D. J., Dankanich, J., Hahne, D., Pencil, E. Peterson, T., Munk, M., "Sample Return Propulsion Technology Development under NASA's ISPT Project," 2011 IEEE Aerospace conference, March 2011, Paper \#1115

[6] Anderson, D. J., Pencil, E., Vento, D., Dankanich, J., Munk, M., Hahne, D., "Propulsion Technology Development for Sample Return Missions under NASA's ISPT Program,” AIAA-2011-5766, 47 $7^{\text {th }}$ Joint Propulsion Conference, San Diego, CA, July 31 - August 3, 2011.

[7] Anderson, D. J., et al, "Status of Sample Return Propulsion Technology Development under NASA's ISPT Project,” 2012 IEEE Aerospace Conference, March 2012, Paper \#1038

[8] Anderson, D. J., Munk, M., Dankanich, J.,Glaab, L., Pencil, Eric E., and Peterson, T., "Status of Sample Return Propulsion Technology Development under NASA's ISPT Project,” IEEEAC Paper \#1038, 2012 IEEE Aerospace Conference, Big Sky, MT, March 3-10, 2012.

[9] Kamhawi, H., Haag, T., Pinero, L., Huang, W., Peterson, T., Manzella, D., Dankanich, J., Mathers, A., Hobson, D., "Overview of the Development of a Low-Cost High Voltage Hall Accelerator Propulsion System for NASA Science Missions," AIAA-2011-5520, 47 AIAA/ASME/SAE/ASEE Joint Propulsion Conference and Exhibit, San Diego, CA, August 2011.

[10] Anderson, D. J., Dankanich, J., Munk, M., Pencil, E., Liou, L., "The NASA In-Space Propulsion Technology Project's Current Products, and Future Directions,” 2010 IEEE Aerospace conference, March 2010, Paper \#1078

[11] Discovery Program Library Website URL: http://discovery.larc.nasa.gov/dpl.html
[12] Congdon, W. M., "Family Systems of Advanced Charring Ablators for Planetary Aerocapture and Entry Missions," 1st NSTC, University of Maryland, June 1921, 2007.

[13] Wright, M. J., Bose, D., and Olejniczak, J., “The Effect of Flowfield-Radiation Coupling on Aeroheating for Titan Aerocapture”, AIAA Paper No. 2004-0484, presented at the 42nd AIAA Aerospace Sciences Conference and Exhibit, Reno, Nevada, Jan. 2004.

[14] Wright, M. J., Bose, D., and Chen, Y. K., "Probabilistic Modeling of Aerothermal and Thermal Protection Material Response Uncertainties," 53rd JANNAF Joint Propulsion Meeting, Dec. 2005.

[15] Willcockson, W. W., NASA Contractor Report (pending), "Final Summary Report: Aerocapture Aeroshell Technologies (AAT) Program,” January 31, 2007.

[16] Miller, K. L. et al., NASA Contractor Report (pending), "Ultralight-weight Ballute Technology for Aerocapture and Aeroassist Missions,” January 2007.

[17] Reza, S., NASA Contractor Report (pending), "Aerocapture Inflatable Decelerator: Lockheed Martin Inflatable Aeroshell Final Report,” January 11, 2007.

[18] Lockwood, M. K.,et al., "Systems Analysis for a Venus Aerocapture Mission,” NASA TM 2006-214291, March 2006.

[19] Lockwood, M. K., et al., "Aerocapture Systems Analysis for a Neptune Mission,” NASA TM 2006-214300, April 2006.

[20] Wright, H. S., et al., "Mars Aerocapture Systems Study," NASA TM 2006-214522, August 2006.

[21] Dankanich, J. W. and McAdams, J., "Interplanetary Electric Propulsion Uranus Mission Trades Supporting the Decadal Survey," AAS 11-189, AAS/AIAA Space Flight Mechanics Meeting, New Orleans, LA, February 13-17, 2011.

[22] Dankanich, J. W., "Electric Propulsion for Small Body Missions," AIAA-2010-6614, 46th AIAA/ASME/SAE/ASEE Joint Propulsion Conference \& Exhibit, Nashville, TN, July 25-28, 2010.

[23] Dankanich, J. W., "Launch Vehicle Savings through Advanced In-Space Propulsion,” 9th Low Cost Planetary Missions Conference, Laurel, MD, June 21 - 23, 2011. 
[24] "NASA's Evolutionary Xenon Thruster (NEXT) Ion Propulsion system Information Summary Aug. 2008,” New Frontiers Program Library Website URL: http://newfrontiers.larc.nasa.gov/NFPL.html

[25] Pinero, L., Benson, S. W., "NEXT Engineering Model PPU Development, Progress and Plans,” AIAA-20115659, 47th AIAA/ASME/SAE/ASEE Joint Propulsion conference and Exhibit, San Diego, CA, August 2011.

[26] New Frontiers Program Library Website URL: http://newfrontiers.larc.nasa.gov/NFPL.html

[27] "Titan Saturn System Mission Final Report (on the NASA Contribution to a Joint Mission with ESA)," January 30, 2009.

[28] Landau, D., Lam, T., and Strange, N., "Broad Search and Optimization of Solar Electric Propulsion Trajectories to Uranus and Neptune,” AAS 09-428.

[29] Dankanich, J. W., Cardin, J., Dien, A., Kamhawi, H., Netwall, C. J., and Osborn, M., "Advanced Xenon Feed System (AXFS) Development and Hot-fire Testing," 45th AIAA/ASME/SAE/ASEE Joint Propulsion Conference, Denver, CO, August 2-5, 2009.

[30] Kelley, A. R., and England, J. D., "Precision Flow Metering of Pulsed and Stead State Rocket Engines," JANNAF JPM/MSS/LPS/SPS Meeting, Colorado Springs, CO, May 3-7, 2010.

[31] Liou, L., Dankanich, J. W., and Alexander, L. L., "NASA In-Space Advanced Chemical Propulsion Development in Recent Years,” 2010 IEEE Aerospace Conference, Big Sky, MT, March 6-13 2010.

[32] Henderson, S., Stechman, C., Wierenga, K., Miller, S., Liou, L., Alexander, L., and Dankanich, J. W., "Performance Results for the Advanced Materials Bipropellant Rocket (AMBR) Engine,” AIAA 2010-6883, 46th Joint Propulsion Conference, Nashville, TN, July 2528, 2010.

[33] “Advanced Material Bi-propellant Rocket (AMBR) Information Summary August 2008,” New Frontiers Program Library Website http://newfrontiers.larc.nasa.gov/NFPL.html

[34] R. Portz, D. Krismer, F. Lu, and S. Miller, "High Pressure Bipropellant Engine System Study,” AIAA2007-5433 42nd AIAA/ASME/SAE/ASEE Joint Propulsion Conference and Exhibit, Sacramento, CA, July, 2006.

[35] Dankanich, J. W., Kamhawi, H., and Mathers, A., "HiVHAC Maximum Operating Power Mission Impacts," IEPC-2009-213, 2009 International Electric Propulsion Conference, Ann Arbor, MI, September 20-24, 2009.
[36] Whiffen, G., "Mystic: Implementation of the Static Dynamic Optimal Control Algorithm for High-Fidelity Low-Thrust Trajectory Design,” AIAA-2006-6741, AIAA/AAS Astrodynamics Specialist Conference, Keystone, CO, August 21-24, 2006.

[37] Sims, J., Finlayson, P., Rinderle, E., Vavrina, M., and Kowalkowski, T., "Implementation of a Low-Thrust Trajectory Optimization Algorithm for Preliminary Design,” AIAA-2006-6746, AIAA/AAS Astrodynamics Specialist Conference, Keystone, CO, August 21-24, 2006.

[38] Ocampo, C., Senent, J. S., and Williams, J., “Theoretical Foundation of Copernicus: A Unified System for Trajectory Design and Optimization,” NASA Technical Reports Server, Document ID: 20100017708; Report Number: JSC-CN-20552, May, 21, 2010.

[39] Samareh, Jamshid A., Maddock, Robert W., and Winski, Richard G., "An Integrated Tool for System Analysis of Sample Return Vehicles,” IEEEAC Paper \#1169, 2012 IEEE Aerospace Conference, Big Sky, MT, March 3-10, 2012. 


\section{BIOGRAPHIES}

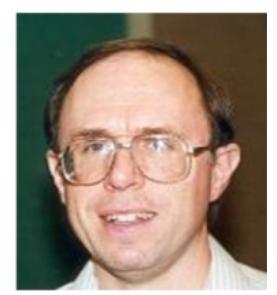

David Anderson is a program manager in the Science Project Office at the NASA Glenn Research Center (GRC). $\mathrm{He}$ is currently the Acting Program Manager for the In-Space Propulsion Technology (ISPT) program, and is the SBIR Spacecraft and Platform Subsystems Topic Manager. Formerly, he managed the advanced Radioisotope Power System (RPS) efforts at NASA GRC, was active with new business development and proposal development activities. He also worked in GRC's Systems Management Office, where he was involved in project management oversight activities and led or was involved in several Center and NASA-wide program/project management process improvement teams or activities. He has a B.S. in Aerospace Engineering from the University of Cincinnati and an M.S. in Engineering Management from the Cleveland State University.

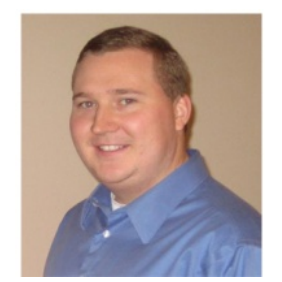

John Dankanich is a Gray Research contractor to the NASA Glenn Research Center. He is the electric propulsion lead systems engineer for the ISPT program. He also serves as a mission and systems analyst for the ISPT progarm and the Glenn Research Center. John has expertise is in mission and systems analyses, electric propulsion systems, and trajectory optimization. He supported propulsion system development, Mars ascent vehicle design, lunar lander guidance simulations, planetary defense studies, and advanced propulsion design and testing. John has a B.S. in Physics and Aerospace Engineering and an M.S. in Aerospace Engineering from Purdue University.

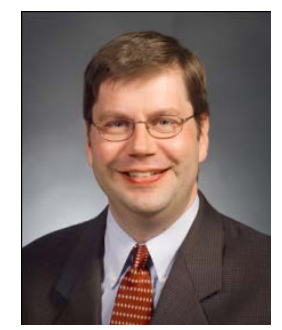

Eric Pencil is Propulsion Projects Area Manager for the In-Space Propulsion Technology Office at NASA Glenn Research Center. $\mathrm{He}$ is responsible for the management and execution of the electric propulsion development tasks for NASA Science missions. Previously he worked as a project/research engineer in the electric propulsion research group in which he worked on various electric propulsion technologies at varying stages of maturity from basic research to flight hardware.

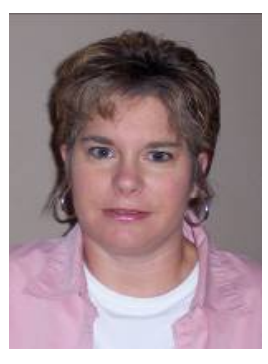

Michelle Munk has been a NASA employee for nearly 20 years, first at the Johnson Space Center, then at the Langley Research Center. She has been involved in Mars advanced mission studies for many years, both robotic and human, contributing interplanetary trajectory analysis and entry and descent analysis. She managed the delivery of International Space Station hardware, and was on the Mars Odyssey aerobraking operations team. In 2002, Ms. Munk accepted a detail assignment to become the Lead Engineer for Aerocapture Technology Development under In-Space Propulsion at Marshall Space Flight Center. She managed the technical work of ISP Aerocapture for nearly five years before becoming the Project Area Manager and returning to Langley in 2007. Ms. Munk is also involved in the Mars Science Laboratory Entry, Descent and Landing Instrumentation (MEDLI) project and contributes to other NASA projects developing entry system technologies. She has a BSAE from Virginia Tech and completed graduate coursework at the University of Houston.

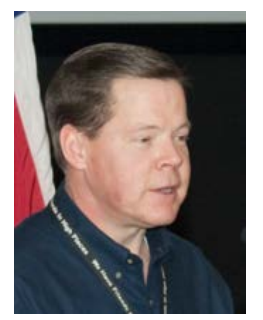

Todd Peterson is a project manager in the Advanced Capabilities Project Office at the NASA Glenn Research Center (GRC). With over 26 years of space flight project experience at NASA GRC, he has extensive propulsion, power and communication system project management experience in human and robotic space flight projects (Space Station, Shuttle/Mir, Deep Space-1, Earth Observer-1, Lunar Reconnaissance Orbiter) and development projects (electric propulsion, chemical propulsion, photovoltaic \& dynamic power systems, microgravity research). He has a B.S. in Mechanical Engineering from the University of Akron and an M.S. in Mechanical Engineering from Cleveland State University. 